\begin{tabular}{l} 
Proceedings of the Institution of \\
Civil Engineers \\
Transport I62 \\
February 2009 Issue TRI \\
Pages 39-45 \\
doi: 10.1680/tran.2009.162.1.39 \\
Paper 700023 \\
Received 10/07/2007 \\
Accepted 03/04/2008 \\
Keywords: \\
car parks/town \& city planning/ \\
transport planning \\
\hline
\end{tabular}
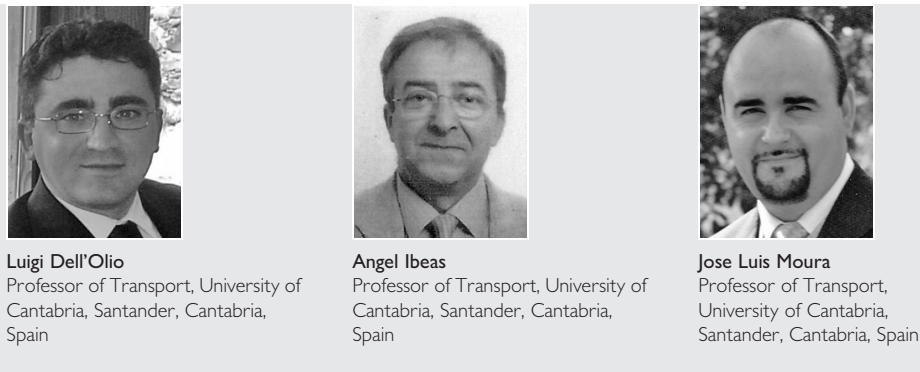

\title{
Paying for parking: improving stated-preference surveys
}

L. Dell'Olio MEng, PhD, CEng, A. Ibeas PhD, CEng and J. L. Moura PhD, CEng

This article describes an experiment which introduced random ranges into the variables used for the design of a stated preference survey and its effects on willingness to pay for parking. User behaviour at the time of parking was modelled to determine their willingness to pay in order to get to their final destination more quickly. Calculating willingness to pay is fundamental during the social and economic assessment of projects. It is important to correctly model how car parks and their users interact in order to get values which represent reality as closely as possible. Willingness to pay is calculated using a stated preference survey and by calibrating multinomial logit models, taking variable tastes into account. It is shown that a value with a low variability can be obtained for willingness to pay by correctly establishing the context of the choice and randomly changing the variables around an average value.

\section{INTRODUCTION}

Calculating willingness to pay (WTP) is especially important when carrying out profitability studies. Feasibility studies for

underground car parks are an example of the importance of the correct evaluation of WTP. The profitability of the car park has to be calculated as exactly as possible to provide information at the time of tendering for its construction and franchise.

Willingness to pay is known to be very sensitive to model specification. At first, even in small towns, paid parking places can prove to be very unpopular with most people. Street space is a scarce commodity belonging to everyone and should be charged for when used individually just like other public property.

Space is critical in areas of high commercial and demographic concentration such as city centres. In Europe parking places are normally regulated by using blue zones (regulation of space and waiting time) and public car parks (regulation by fee), which can be located either on the surface or underground. Rather than being profit orientated, policies for regulating street parking should be aimed at improving traffic flow, favouring the rotation of parking spaces and freeing up areas for loading and unloading at certain times. Therefore, when new urban projects are started, such as shopping centres, cinemas or buildings for other leisure activities, any public and private projects should include a study on the need for parking places and their probable effects on traffic flow in and around the site location.
The closest study to this work is that of Axhausen and Polak, ${ }^{1}$ which models parking choice using a stated preference survey. A similar study can be found in the article by Hensher and King. ${ }^{2}$ Various types of parking were used in a study by Van der Goot ${ }^{3}$ in which a logit model was applied to model the choice of parking as a function of attributes. Other relevant studies on modelling user behaviour when parking are those of Hunt, ${ }^{4}$ Ergün $^{5}$ and Gillen ${ }^{6}$ in which no mention is made of the correct calculation of WTP nor the problem of its variability with respect to the specification of the utility functions during the design of the discrete choice models. In fact none of the above-mentioned works highlight this latter problem.

The international literature also provides many examples of studies made on the impact of parking pricing policies, ${ }^{7-10}$ parking simulation models such as Pamela ${ }^{11}$ and the development of parking choice models for special events such as in the article by Sattayhatewa and Smith. ${ }^{12}$

Interesting work has also been done on car parks and accessibility such as that of Ferguson ${ }^{13}$ who studied user responses to changes made in the supply, location, price and accessibility of parking.

With the exception of the study by Hess and Polak, ${ }^{14}$ no other relevant studies are known which try to model user behaviour when choosing between different types of parking and which also calculate WTP to save time to final destination.

The objective of this investigation was to simulate user behaviour when parking. A stated preference survey was used to present the user with different situations. A trial was made at introducing random ranges into the levels of the variables used in the design of a stated preference survey and a study was made of their effects on willingness to pay.

The study and modelling of user behaviour using discrete choice models allows a calculation to be made for the user's willingness to pay in exchange for quicker or improved access to final destination. Willingness to pay is a fundamental variable which is used, or should be used, in the social and economic assessment of construction projects and the running of car parks because it provides a sufficiently clear idea of the correct tariff to charge and takes into account other points of importance to the user. There are several relevant studies on this subject. 


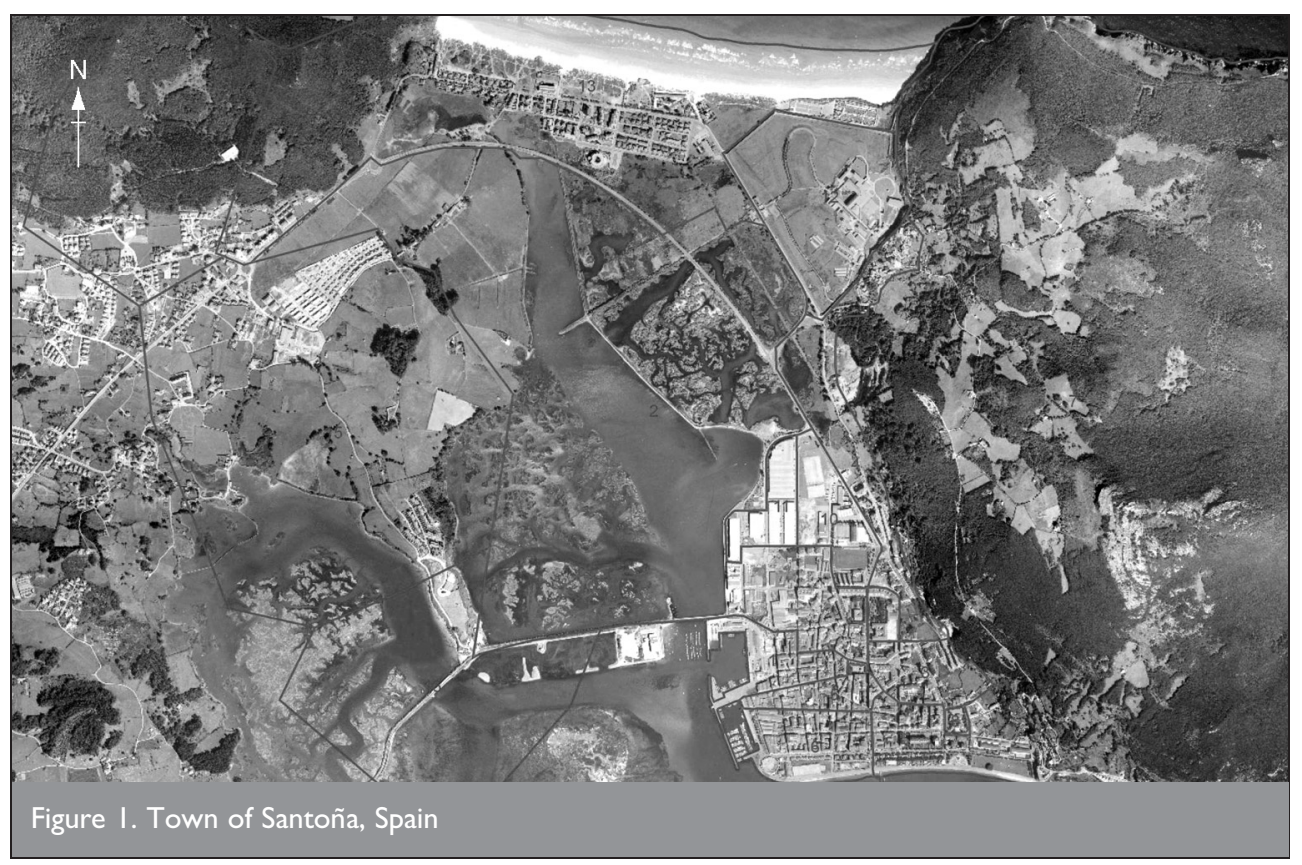

Free street parking is the current situation in the area under study.

\section{METHODOLOGY}

A stated preference survey was initially designed to find out the potential demand of travellers by car going to the area under study, and also to study the variables which condition each user at the time of parking. Using the results of the survey, a series of multinomial discrete choice models were run to define user distribution between the three types of parking available.

These models are based on random utility theory. It is

This paper explains how a real problem was solved on willingness to pay and the effect of pricing policy for an underground car park in the town of Santoña in Cantabria, Northern Spain. It forms part of the studies performed by the local authorities for the construction project and for the tendering of the concession for the underground car park. Santoña is a coastal and tourist town (Figure 1) of less than 3000 inhabitants, the population multiplies during the summer due to tourism and it also has quite a significant fishing fleet.

The regional government of Cantabria proposed the construction of a leisure area close to the fishing port. This area would include restaurants, night clubs and shops. The design would be complemented by the creation of a large pedestrian-only area. The problem of parking was raised for the people visiting this area.

The local authorities commissioned a feasibility study for the construction and running of an underground car park close to the said leisure areas.

This technical, social and economic feasibility study included the reorganisation of existing surface parking as well as the design and management of the future proposed underground car park.

The following requirements had to be resolved for the study.

(a) Define the supply of places needed to meet the needs of users wanting to reach the leisure area taking into account the number of street parking places that would disappear due to pedestrianisation.

(b) Consider three possible choices for the user: (i) free street parking (SP); (ii) paid street parking [regulated street parking (OLA)]; and (iii) parking in the yet-to-be-constructed underground car park (UP).

(c) Calculate the distribution of users between the three available parking possibilities.

(d) Calculate WTP by hour for parking in the underground car park, in order to reduce the distance to their final destination (from the underground car park). assumed that this utility can be represented by two components.

(a) A systematic or representative component $V_{i q}$, which is a function of measured attributes $(x)$.

(b) A random component $\varepsilon_{i q}$, representing individual idiosyncrasies and tastes, as well as any measurement or observation errors made by the modeller.

Therefore

$$
U_{i q}=V_{i q}+\varepsilon_{i q}
$$

The first part of the sum can be expressed as

$2 \quad V_{i q}=\sum_{k=1}^{k} \theta_{i k} \cdot x_{i k q}$

where the parameters $\theta$ are assumed to be constant for all individuals, although they can vary between different alternatives. These parameters are usually estimated by using the maximum likelihood method.

Once the values of the $\theta$ parameters are established then willingness to pay in order to reduce access time to final destination can be calculated.

An individuals' willingness to pay was calculated with the formula

WTP $=-\frac{d c_{i}}{d t_{i}}=\frac{\partial V_{i} / \partial t_{i}}{\partial V_{i} / \partial c_{i}}$

Note that it represents the value of time that is therefore the marginal rate of substitution between journey time and cost and measures an individual's WTP for time savings. It is calculated as the derivative of the cost of choice $i\left(c_{i}\right)$ with respect to time $\left(t_{i}\right)$ with $V_{i}$ being the utility associated with choice $i$. This means that as the time saved by the users increases they are prepared to pay more to use the underground car park. To a certain extent 


\begin{tabular}{|c|c|c|c|}
\hline Variable & Level I & Level 2 & Random variants \\
\hline $\begin{array}{l}\text { Tariff underground car park (TUP) } \\
\text { Tariff OLA (TOLA) }\end{array}$ & $\begin{array}{l}0.8 € / \mathrm{h} \\
0.6 € / \mathrm{h}\end{array}$ & $\begin{array}{l}1.5 € / h \\
0.8 € / h\end{array}$ & \\
\hline Access time to parking (ATUP) & & & $5+3\left(2 \xi_{1}-1\right) \min$ \\
\hline Access time to OLA (ATOLA) & & & $8+3\left(2 \xi_{2}-1\right) \min$ \\
\hline Access time to street (ATS) & $10 \mathrm{~min}$ & $15 \mathrm{~min}$ & \\
\hline Time to destination underground car park (DTUP) & & & $10+2\left(2 \xi_{3}-1\right) \min$ \\
\hline Time to destination paid street parking (DTOLA) & $10 \mathrm{~min}$ & $15 \mathrm{~min}$ & \\
\hline Time to destination free street parking (DTS) & $10 \mathrm{~min}$ & $15 \mathrm{~min}$ & \\
\hline
\end{tabular}

measurement is being taken not only of each user's WTP but also the average WTP depending on the location chosen by the authorities to construct the car park. As shown in Ibeas et al., ${ }^{15,16}$ this WTP can be considered as a close approximation to the tariff to be charged by the car park under consideration.

\section{STATED PREFERENCE WITH RANDOM RANGES FOR LEVELS OF VARIABLE}

The design of stated preference surveys is amply covered in the international literature, the accepted work of reference is that of Louviere et al. ${ }^{17}$

There are also two relevant articles by Sandor and Wedel ${ }^{18,19}$ and also that of Huber and Zwerina. ${ }^{20}$ Another important current work is that of Street et al., ${ }^{21}$ which compares two different survey designs to test their efficiency.

The present work proposes something similar, comparing the classic design obtained from Guide to Forecasting Travel Demand with Direct Utility Assessment ${ }^{22}$ with a similar design which introduces random ranges into single level variables.

The present study considered five variables each having two levels $\left(2^{5}\right)$. Experimental plan code no. 4a was chosen, having a corresponding test number of 8 , without taking into account all the main effects of the independent factors. Master plan 2 corresponds to this experiment (columns 3, 4, 5, 6 and 9). The variables used are shown in Table 1.

Problems appeared (excessively high value for WTP) in a previous study ${ }^{16}$ performed by the authors on the same car park in the calculation of the discrete choice models. These were caused by poor variability in interviewee answers when the situations were changed. This problem can be solved by providing the interviewees with more varied situations by inserting random ranges into the variables at one unique level, thereby providing the highest range of possibilities (situations). To achieve this, the main variables (ATUP, ATOLA, DTUP) were calculated from a predetermined average value, thus obtaining new values by generating random numbers of between zero and one. Table 1 shows that there are five variables of two levels and another three obtained for each experiment, generating random numbers $\xi_{i}$ between 0 and 1 . The tariffs for parking in the underground car park (TUP) are seen to be higher than the tariffs for paid street parking (TOLA), contrary to what normally happens in other countries. This is because underground car parks are manned and offer much higher levels of security against car crime and accidents than those offered by surface parking. The Spanish user has been shown to be willing to pay extra for higher levels of security. Underground car parks also offer easier payment and better comfort than street parking. Access time to parking (ATUP) is taken to be the time from entering the car park to finding a place and parking the vehicle. Access time to parking in OLA (ATOLA) or in free street parking $(A T S)$ is taken to be the time from entering the surface parking zone to finding a place and parking the vehicle. The values given to ATUP and ATOLA are different. This is because in similar cases it was found to be easier to find a parking place in an underground car park than in the street. The value of this variable may appear to be high, but it isn't considering the limited supply of surface parking places and a certain reluctance to park in the underground car park, because, in spite of the greater security offered, there are clear congestion problems that considerably increase access time. Access time to final destination under any of the hypotheses (DTUP, DTOLA and DTS), is taken to be the time the user spends from the moment of parking to reaching their final destination point. Access time to final destination was approximately calculated from a pilot survey which allowed us to fix certain ranges that were as close as possible to reality. From existing studies of car parks in similar areas it was seen that access time to underground car park (ATUP) can vary from 2 to $8 \mathrm{~min}$ depending on how busy the car parks are. Therefore, this variable was given a variability of $5+3\left(2 \xi_{1}-1\right) \mathrm{min}$. Access time for parking in OLA (ATOLA) was given a value of $8+3\left(2 \xi_{2}-1\right) \mathrm{min}$. Time to destination from an underground car park (DTUP) is $10+2\left(2 \xi_{3}-1\right)$ min, owing to the distance between the proposed underground car park and the leisure area. The random ranges have little effect in changing the single level variables around the average value, the objective being to present the interviewees with an ample range of situations which provide greater variability in the answers (choices). The interviewees were asked about the following other variables: their sex, age, income and frequency of journey (Table 2). The eight situations could finally be presented as shown in Table 3.

\section{DATA COLLECTION}

Two hundred valid interviews were carried out on car users within a radius of $500 \mathrm{~m}$ around the area where the underground car park would be constructed. The choice of the survey area was due to the small size of the town and justified by an origin-destination survey performed in Santoña, which found that the average person travelling on foot did not walk more than $500 \mathrm{~m}$. This area was divided into zones for the stated preference survey. Zone 1 was where the underground car park would be constructed (and zone 2 limits the area where street parking would be banned (within a radius of $500 \mathrm{~m}$ around the car park).

Easily understood graphic cards were designed so the user could better understand the surveyed situations. This would simplify 


\begin{tabular}{|c|c|c|}
\hline Survey time: & \multicolumn{2}{|c|}{ Place of survey (street and no.): } \\
\hline Sex: $\square$ Male $\square$ Female & Age: & Are you from Santoña? $\square$ Yes $\square$ No \\
\hline Starting point of journey: & & Destination (street or area within Santoña): \\
\hline Reason for journey: $\square$ Home & e $\square$ Work $\square$ Shopping & $\square$ Leisure $\quad \square$ Other \\
\hline Make and model of vehicle: & & Age of vehicle: \\
\hline $\begin{array}{l}\text { Level of income: } \\
\square<600 € \\
\square 600-1200 € \\
\square 1200-1500 € \\
\square>2500 €\end{array}$ & $\begin{array}{l}\text { Frequency of journey: } \\
\square \text { Occasional } \\
\square \text { Monthly } \\
\square \text { Weekly } \\
\square \text { Daily }\end{array}$ & If daily, how many times per day? \\
\hline
\end{tabular}

Table 2. Other survey data

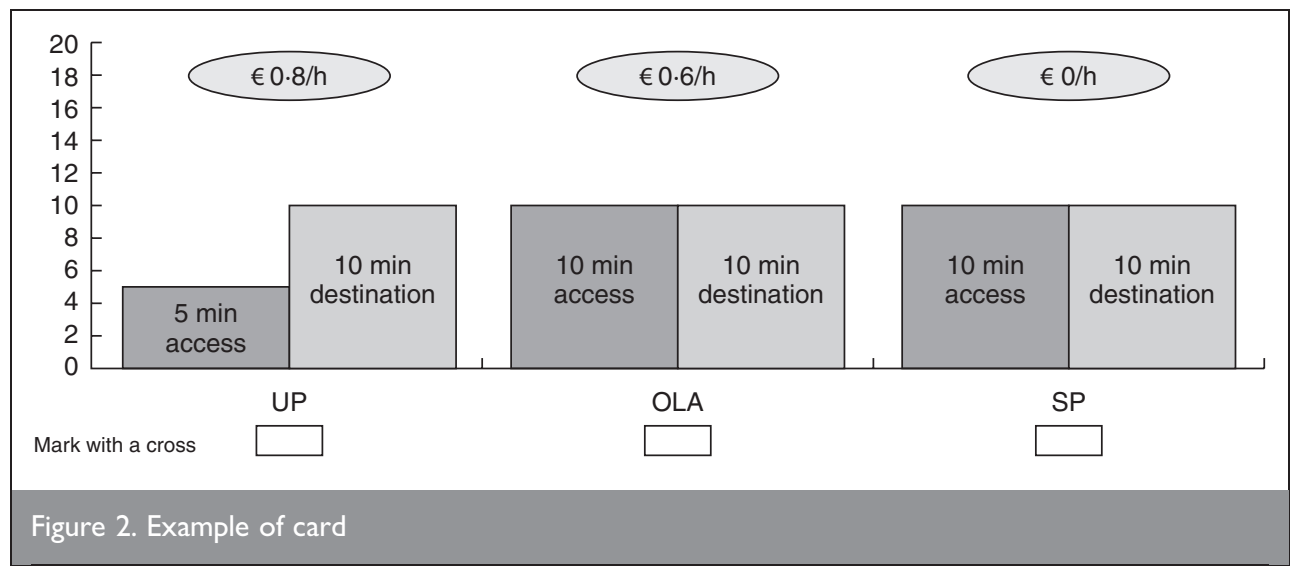

the answers which would then be compared between the different attributes influencing the choice of parking type.

The time spent parked was not asked nor was it included in the experimental design because, in a previous study ${ }^{16}$ this variable proved to be of little significance. This was because interviewees appeared to have difficulty understanding (and calculating) the economic implications of a long stay in a car park. The survey was carried out in the following way.

General situation: Let's suppose that you are going to make the same journey as today and you have to park for one hour. The possibilities are

(a) park in the underground car park (UP)

(b) park in paid street parking (OLA)

(c) park in free street parking (SP).
Answer for the following situations (Figure 2): (the interviewee is shown the eight graphic cards).

After showing all the cards to the interviewee, ask:

'From 1 to 5 what importance would you give to the fee?'

'From 1 to 5 what importance would you give to access time to parking?'

'From 1 to 5 what importance would you give to the time to your destination?'

The survey showed that $60 \cdot 5 \%$ of the users entering the study area were men and that $59 \cdot 3 \%$ were residents of Santoña.

Work was the main reason for travelling $(57 \cdot 0 \%)$ followed by leisure and shopping (26.7\%). Table 4 shows the results for the distributions according to age, income and journey frequency.

The average age was 39 years, average income was $€ 1373$ / month and the average journey frequency into the study area was 1.5 trips/day. Discrete choice models were estimated using this data and the data obtained from the stated preferences survey. The results are presented in the following section.

\section{ESTIMATION AND RESULTS}

In order to calculate WTP in order to reduce access time to final destination, an accessibility variable was included (time taken to park plus time taken in reaching final destination) for each choice (depending on the choice, it would be equal to ATUP + DTUP, ATOLA + DTOLA and ATS +DTS). A 'context of choice' had to be introduced.

The 'context of choice' consisted of the user's dilemma of whether to park in the street (paying in OLA or free (SP)) or in the proposed underground car park (UP), with all the implied consequences of savings in time or money.

\begin{tabular}{|lcccccccc|}
\hline Situation & TUP: $€ / \mathrm{h}$ & TOLA: $€ / \mathrm{h}$ & ATUP: $\min$ & ATOLA: $\min$ & ATS: $\min$ & DTUP: $\min$ & DTOLA: min & DTS: $\min$ \\
\hline 1 & 0.8 & 0.6 & $5+3\left(2 \xi_{1}-1\right)$ & $8+3\left(2 \xi_{2}-1\right)$ & 10 & $10+2\left(2 \xi_{3}-1\right)$ & 10 & 10 \\
2 & 0.8 & 0.6 & $5+3\left(2 \xi_{1}-1\right)$ & $8+3\left(2 \xi_{2}-1\right)$ & 10 & $10+2\left(2 \xi_{3}-1\right)$ & 15 & 15 \\
3 & 0.8 & 0.8 & $5+3\left(2 \xi_{1}-1\right)$ & $8+3\left(2 \xi_{2}-1\right)$ & 15 & $10+2\left(2 \xi_{3}-1\right)$ & 10 & 15 \\
4 & 0.8 & 0.8 & $5+3\left(2 \xi_{1}-1\right)$ & $8+3\left(2 \xi_{2}-1\right)$ & 15 & $10+2\left(2 \xi_{3}-1\right)$ & 15 & 10 \\
5 & 1.5 & 0.6 & $5+3\left(2 \xi_{1}-1\right)$ & $8+3\left(2 \xi_{2}-1\right)$ & 15 & $10+2\left(2 \xi_{3}-1\right)$ & 10 & 15 \\
6 & 1.5 & 0.6 & $5+3\left(2 \xi_{1}-1\right)$ & $8+3\left(2 \xi_{2}-1\right)$ & 15 & $10+2\left(2 \xi_{3}-1\right)$ & 15 & 10 \\
7 & 1.5 & 0.8 & $5+3\left(2 \xi_{1}-1\right)$ & $8+3\left(2 \xi_{2}-1\right)$ & 10 & $10+2\left(2 \xi_{3}-1\right)$ & 10 & 10 \\
8 & 1.5 & 0.8 & $5+3\left(2 \xi_{1}-1\right)$ & $8+3\left(2 \xi_{2}-1\right)$ & 10 & $10+2\left(2 \xi_{3}-1\right)$ & 15 & 15 \\
\multicolumn{7}{l}{ Table 3. Experimental design: Situations presented to the interviewees } \\
\hline
\end{tabular}




\begin{tabular}{|c|c|c|c|c|c|}
\hline \multicolumn{2}{|l|}{ Age: years } & \multicolumn{2}{|l|}{ Income: $€ /$ month } & \multicolumn{2}{|c|}{ Journey frequency: trip/day } \\
\hline$<24$ & $3.5 \%$ & $<600$ & $0.0 \%$ & I & $62 \cdot 8 \%$ \\
\hline $25-34$ & $47 \cdot 7 \%$ & $600-1200$ & $41.9 \%$ & 2 & $29.1 \%$ \\
\hline $35-44$ & $15 \cdot 1 \%$ & $1200-1500$ & $16 \cdot 3 \%$ & 3 & $3.5 \%$ \\
\hline $45-54$ & $16 \cdot 3 \%$ & $1500-2500$ & $41 \cdot 9 \%$ & & $2 \cdot 3 \%$ \\
\hline $55-64$ & $12 \cdot 8 \%$ & $>2500$ & $0.0 \%$ & 5 & $2.3 \%$ \\
\hline$>65$ & $4 \cdot 7 \%$ & & & & \\
\hline Average age & $39 \cdot 3$ & Average income & $1373 \cdot 2$ & $\begin{array}{l}\text { Average journey } \\
\text { frequency }\end{array}$ & 1.5 \\
\hline
\end{tabular}

\begin{tabular}{|c|c|c|c|}
\hline Explanation & Measurement unit & Abbreviation/variable & Associated parameters \\
\hline Constant car park & - & - & $P A$ \\
\hline Constant OLA & - & - & PO \\
\hline Constant street & - & - & PS \\
\hline (Tariff/income) of the parking & {$[(€ / h) /(€ / h)]$} & AFP & $F P$ \\
\hline (Tariff/income) of the OLA & {$[(€ / h) /(€ / h)]$} & AFO & FO \\
\hline Time from car park & (h) & ATP & $T P$ \\
\hline Time from OLA & (h) & ATO & TO \\
\hline Time from street & (h) & ATS & TS \\
\hline Time from car parking/OLA & (h) & ATP and ATO & $\begin{array}{c}\text { TPO (common parameter } \\
\text { in } P \text { and } O L A)\end{array}$ \\
\hline Sex & - & ASE & SE \\
\hline Age & - & $A A G$ & $A G$ \\
\hline Age car park & _- & AAG & $A P G$ \\
\hline Age OLA & - & $A A G$ & AOG \\
\hline Frequency daily journeys & (journeys/day) & AFPD & FPD \\
\hline Income & $(€ / \mathrm{h})$ & AINC & INC \\
\hline
\end{tabular}

The variables used and their associated parameters are shown in Table 5. Several multinomial logit discrete choice models were run to calculate willingness to pay to reduce access time to final destination (Table 6).
As can be seen in Tables 5 and 6 the effect of income was evaluated following the results of the work done by Jara-Diaz and Videla. ${ }^{23}$ This produced a substantial improvement in the running of the models.

\begin{tabular}{|c|c|c|c|c|c|}
\hline & $\begin{array}{l}\text { Model I } \\
\text { Coeff. }\end{array}$ & $\begin{array}{c}\text { Model } 2 \\
\text { Coeff. }\end{array}$ & $\begin{array}{c}\text { Model } 3 \\
\text { Coeff. }\end{array}$ & $\begin{array}{c}\text { Model } 4 \\
\text { Coeff. }\end{array}$ & $\begin{array}{c}\text { Model } 5 \\
\text { Coeff. }\end{array}$ \\
\hline$P A$ & $2 \cdot 698(5 \cdot 1)$ & $2 \cdot 936(5 \cdot 4)$ & $3.507(6.0)$ & & \\
\hline PO & & & & $-3 \cdot 745(-3 \cdot 8)$ & $-3 \cdot 883(-3 \cdot 3)$ \\
\hline PS & & & & $-2.759(-3.6)$ & $-2 \cdot 914(-3 \cdot 7)$ \\
\hline FP & $-21.896(-11.5)$ & $-22 \cdot 36 \mid(-11.5)$ & $-23.080(-11.4)$ & $-21.012(-10.5)$ & $-21.436(-10 \cdot 4)$ \\
\hline FO & $-27.508(-8.6)$ & $-26.911(-8.3)$ & $-26.518(-8.1)$ & $-22 \cdot 228(-5 \cdot 0)$ & $-22.963(-5 \cdot 1)$ \\
\hline TPO & $-3 \cdot 588(-3 \cdot 2)$ & $-3.428(-3.0)$ & $-3.678(-3 \cdot 2)$ & & \\
\hline$T P$ & & & & $-3.749(-2 \cdot 0)$ & $-4 \cdot 057(-2 \cdot 1)$ \\
\hline TO & & & & $-2 \cdot 889(-1 \cdot 7)$ & $-2.675(-1.6)$ \\
\hline$T S$ & $-1.883(-2.0)$ & $-2 \cdot 066(-2 \cdot 2)$ & $-2 \cdot 284(-2 \cdot 4)$ & $-2.585(-2.5)$ & $-2.604(-2.5)$ \\
\hline$S E$ & & $-0.629(-2.5)$ & $-0.555(-2.2)$ & & \\
\hline AG & $0.063(6.7)$ & $0.069(7.0)$ & $0.067(6.7)$ & $0.068(6.6)$ & \\
\hline APG & & & & & $0.072(6.4)$ \\
\hline AOG & & & & & $0.057(3 \cdot 3)$ \\
\hline FPD & & & $-0 \cdot 370(-3 \cdot 7)$ & $-0 \cdot 282(-3 \cdot 1)$ & $-0.363(-3.6)$ \\
\hline FPS & & & & $-2 \cdot 289(-2 \cdot 1)$ & $-2 \cdot 709(-2 \cdot 3)$ \\
\hline Log likelihood function & $-315 \cdot 595$ & $-3|2 \cdot 53|$ & $-304 \cdot 180$ & -306.055 & $-302 \cdot 827$ \\
\hline WTP & 0.678 & 0.635 & 0.660 & 0.683 & 0.716 \\
\hline Confidence interval WTP & {$[0.659,0.698]$} & {$[0.616,0.653]$} & {$[0.641,0.679]$} & {$[0.663,0.702]$} & {$[0.695,0.736]$} \\
\hline
\end{tabular}


In these models all the parameters were of the correct sign and all the variables used are significant to a 95\% confidence level.

Model 5 turned out to be the best. It considered the financial factor (by using the variable 'Tariff/income') as well as a systematic variation in taste, which was obtained by interacting the tariff variable $(A F P)$ with the sex variable $(A S E)$, the age variable $(A A G)$ and the daily trip frequency variable $(A F P D)$. The specification of model 5 is as follows

$$
4 \begin{aligned}
V_{\mathrm{UP}}= & F P \times A F P+F P S \times A F P \times A S E+T P \times A T P \\
& +A P G \times A A G \\
V_{\mathrm{OLA}}= & P O+F O \times A F O+T O \times A T O+A O G \times A A G \\
V_{\mathrm{SP}}= & P S+T S \times A T S
\end{aligned}
$$

Specifying the utility functions of the three choices available: underground car park $\left(V_{\mathrm{UP}}\right)$, paid surface parking $\left(V_{\mathrm{OLA}}\right)$ and free surface parking $\left(V_{\mathrm{SP}}\right)$. The significance of each parameter and variable is explained in Table 5.

The value of WTP for parking in the underground car park $\left(W T P_{\mathrm{UP}}\right)$ for model 5 is obtained in the following way

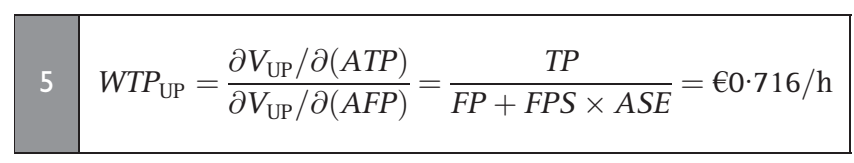

In this type of study it is important to calculate each user's WTP and check its variability. Several studies have proposed methods for calculating WTP confidence intervals. Those that stand out are the works of Armstrong et al., ${ }^{24}$ which is a very valid method in the case of using multinomial logit models such as the one used here, as well as another method, ${ }^{25}$ which adapts well to cases that consider systematic variation in taste. Models 4 and 5 in this article take into account systematic variation in taste and interact the variables $A F P$ and $A F O$ (tariff/income) with the variable ASE (sex) (see parameter $F P S$ ). Other interactions were tried without having much success.

It is interesting to see how WTP in order to reduce access time to final destination is kept practically constant and does not change much when the model specification is changed. For example Hensher ${ }^{26,27}$ states that 'more restrictive models tend to underestimate the value of time'; however, $\operatorname{Train}^{28}$ and Carlsson ${ }^{29}$ point out that 'substantial variations should not be found between different models'. The latter is what happens in the present work, $W T P$ only varies between $€ 0 \cdot 660 / \mathrm{h}$ in model 3 and $€ 0 \cdot 716 / \mathrm{h}$ in model 5.

Considering the best model (model 5), Table 6 shows an average $W T P$ of $€ 0 \cdot 716 / \mathrm{h}$ with a deviation of $€ 0 \cdot 021 / \mathrm{h}$, only 2 euro cents (95\% of the confidence level). These results come from the microeconomic analysis based on the preferences expressed by the users. As in all stated preferences studies techniques exist that can avoid any possible bias in the answers given by the users which could affect the results of the study.

The previously mentioned work ${ }^{16}$ done on the same study area considered a binary choice (underground car park or free street parking) without using random ranges and obtained very heterogeneous WTP values following the model specification which were rather higher than the values obtained in the present work.

Consequently, it can be stated that the use of a more realistic choice context such as the one proposed here, and the introduction of random ranges into single-level variables, helps to get more stable and coherent $W T P$ values closer to those expected in reality.

\section{CONCLUSIONS}

This work demonstrates the importance of modelling user behaviour when parking.

Its importance depends on two factors; first, correctly determining the demand for places in the car park by good survey design and, second, determining the user's willingness to pay to increase accessibility to final destination.

Based on the modelling carried out it can be shown that if the choice context is not chosen well and the variables influencing choice are not modelled adequately, then the result may be $W T P$ values which can vary greatly depending on the specification of the model. All this is relevant for the car park feasibility studies when it comes to fixing the final parking tariff as can be seen in Ibeas et al. ${ }^{16}$ which overestimated the WTP values.

Using random ranges in the model's variables not only implicates the use of eight situations in the design of the survey but also allows for a much greater variety in the answers given by the interviewees which makes the calibration of the discrete choice models easier.

Considering the effect of income and the systematic variation in taste (models 4 and 5 in Table 6) improves the running of the model without influencing the calculation of WTP.

The inclusion of certain variables in the model can generate bias when calculating willingness to pay. In many cases it would be better to simplify their specification by using only those variables which the user will definitely take into account when making their choice.

In practical terms all of this means that to correctly plan policy for both underground and street parking then these types of studies should be made together (UP, OLA, SP). The corresponding modelling would then provide information on the attitude of the users when faced with the choice of where to park.

Finally, it is worth pointing out that the techniques presented here represent an important advance in improving the accuracy of technical, economic and social viability studies for projects involving underground car parks. Apart from the work presented here it is also very important to get reliable information about the demand for future car parking. This is obtained by doing quality stated preferences surveys around the area where the car park will be constructed and, if there are available resources, complementing these surveys with household surveys which help us estimate more accurately the demand induced by the future car park. 


\section{REFERENCES}

1. Axhausen K. W. and Polak J. W. Choice of parking - stated preference approach. Transportation, 1991, 18, No. 1, 59-81.

2. HENSHER D. A. and King J. Parking demand and responsiveness to supply, pricing and location in the Sydney central business district. Transportation Research Part A - Policy and Practice, 2001, 35, No. 3, 177-196.

3. VAN DER GOOT D. A model to describe the choice of parking places. Transportation Research Part A - Policy and Practice, 1982, 16, No. 2, 109-115.

4. HunT J. D. Parking location choice: insights and representations based on observed behaviour and hierarchical logit modelling formulation. Proceedings of the 58th Annual Meeting of the Institute of Transportation Engineers, Vancouver. Institute of Transportation Engineers, Washington, D.C., USA, 1988, pp. 439-446.

5. ERGÜN G. Development of a downtown parking model. Highway Research Record 1971, 369, 118-134.

6. GILLEN D. W. Parking policy, parking location decisions and distribution of congestion. Transportation, 1978, 7, No. 1, 69-85.

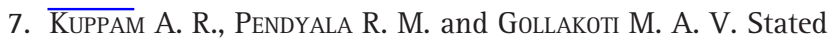
response analysis of the effectiveness of parking pricing strategies for transportation control. Transportation Finance, Economics, and Management, 1998, 1649, 39-46.

8. Bianco M. J. Effective transportation demand management - combining parking pricing, transit incentives, and transportation management in a commercial district of Portland, Oregon. High-Occupancy Vehicle Systems and Demand Management, 2000, 1711, 46-54.

9. Hess D. B. Effect of free parking on commuter mode choice - Evidence from travel diary data. Transit Planning, Intermodal Facilities, and Marketing, 2001, 1753, 35-42.

10. SHIFTAN Y. and BuRD-EDEN R. Modeling response to parking policy. High-Occupancy Vehicle Systems and Demand Management, 2001, 1765, 27-34.

11. VAn der Waerden P., Timmermans H. and Borgers A. PAMELA - Parking analysis model for predicting effects in local areas. High-Occupancy Vehicle Systems and Demand Management, 2002, 1781, 10-18.

12. Sattayhatewa P. and SMith R. L. Development of parking choice models for special events. Transportation Planning and Analysis, 2003, 1858, 31-38.

13. Ferguson E. Parking and accessibility. In Access to Destinations (LEVINSON D. and KRIZEK K. J. (eds)). Elsevier, Oxford, UK, 2005, pp. 377-406.

14. Hess S. and PolaK J. W. Mixed logit estimation of parking type choice. Proceedings of the 83rd Annual Meeting of the Transportation Research Board. Transportation Research Board, Washington, D.C., USA, 2004, pp. 35-43.
15. Ibeas A., Dell'Olio L. and Moura J. L. Willingness to pay for better access to final destination by using an underground car park. Proceedings of the 86th Annual Meeting of the Transportation Research Board. Transportation Research Board, Washington, D.C., USA, 2007, pp. 1-13.

16. Ibeas A., Dell'Olio L. and Moura J. L. Willingness to pay for access time saving: some evidences. Proceedings of Euro Working Group on Transportation, Bari, Italy, 2006, pp. 322-327.

17. LOUVIERE J., Hensher D. and Swatt J. Stated Choice Methods: Analysis and Applications. Cambridge University Press, Cambridge, 2001.

18. SANDor Z. and Wedel M. Profile construction in experimental choice designs for mixed logit models. Marketing Science, 2002, 21, No. 4, 455-475.

19. SANDOR Z. and WEDEL M. Heterogeneous conjoint choice designs. Journal of Marketing Research, 2005, 42, No. 2, 210-218.

20. HUBER J. and ZwERINA K. The importance of utility balance in efficient choice designs. Journal of Marketing Research, 1996, 33, No. 3, 307-317.

21. Street D. J., Burgess L. and Louviere J. J. Quick and easy choice sets: constructing optimal and nearly optimal stated choice experiments. International Journal of Research in Marketing, 2005, 22, No. 4, 459-470.

22. Kocur G., Adler T., HyMAN W. and Aunet B. Guide to Forecasting Travel Demand with Direct Utility Assessment. US Department of Transportation, Washington, D.C., 1982, Report No. UMTA-NH-11-1-82.

23. JARA-DiAZ S. and Videla J. Detection of income effect in mode choice-theory and application. Transportation

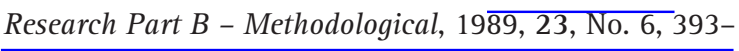
400.

24. Armstrong P., Garrido R. and Ortuzar J. D. Confidence intervals to bound the value of time. Transportation Research Part E - Logistics and Transportation Review, 2001, 37, No. 2-3, 143-161.

25. Espino R., ORTUZAR J. D. and Roman C. Confidence interval for willingness to pay measures in mode choice models. Networks and Spatial Economics, 2006, 6, No. 2, 81-96.

26. HENSHER D. A. The valuation of commuter travel time savings for car drivers: evaluating alternative model specifications. Transportation, 2001, 28, No. 2, 101-118.

27. Hensher D. A. Measurement of the valuation of travel time savings. Journal of Transport Economics and Policy, 2001, 35, No. 1, 71-98.

28. TRAIN K. E. Recreation demand models with taste differences over people. Land Economics, 1998, 74, No. 2, 230-239.

29. CARLSSON F. The demand for intercity public transport: the case of business passengers. Applied Economics, 2003, 35, No. 1, 41-50.

\section{What do you think?}

To comment on this paper, please email up to 500 words to the editor at journals@ice.org.uk

Proceedings journals rely entirely on contributions sent in by civil engineers and related professionals, academics and students. Papers should be 2000-5000 words long, with adequate illustrations and references. Please visit www.thomastelford.com/journals for author guidelines and further details. 